BOUDICCA'S HELMET:

WARRIOR WOMEN OF BRITISH ANTHROPOLOGY

Eleanor Rimoldi ${ }^{1}$

Books Reviewed:

MARY DOUGLAS:

UNDERSTANDING SOCIAL THOUGHT AND CONFLICT

By Perri 6 and Paul Richards

New York, Oxford: Berghahn Books, 2017, 241 pp.

ISBN 978-1-78533-422-1 (hardback), ISBN 978-1-78533-561-7 (paperback), eISBN 978-1-78533-423-8 (eBook).

(Includes a separate reference section for cited works by Mary Douglas.)

REDESCRIBING RELATIONS: STRATHERNIAN CONVERSATIONS ON ETHNOGRAPHY, KNOWLEDGE AND POLITICS

Edited by Ashley Lebner

New York,Oxford: Berghahn Books, 2017, 252 pp.

ISBN 978-1-78533-392-7 (hardback), ISBN 978-1-78533-457-3 (paperback) eISBN 978-1-78533-393-4 (eBook).

(Includes an Appendix: Marilyn Strathern: A Complete Bibliography. Professor Dame Marilyn Strathern FBA. January 2015)

In 1989 when Mary Douglas reviewed Marilyn Strathern's The Gender of the Gift: Problems with Women and Problems with Society in Melanesia, her comments were headed 'A Gentle Deconstruction'2 but the tone was much more combative. The title of her review is a subtle sideswipe in that it is taken from Strathern herself. As Douglas points out, 'what she [Strathern] calls a "gentle deconstruction" of existing readings on Melanesian culture is a devastating criticism, yet she manages not to have authored any criticisms herself' (p.18). Douglas' review illustrates the intellectual strength of both women as well as the differences between their theoretical positions. I have an image of women warriors locking horns. However, in the two books under review, as far as I could see, Strathern is not referenced in the book about Douglas, and vice versa. 
In any case, it would be a proxy war, fought by their interlocutors.

\section{SLOW THEORY}

Mary Douglas: Understanding Social Thought and Conflict is by Perri 6 (David Ashworth) whose work has focused on institutional and public management, and Paul Richards, an anthropologist focused on development, risk and institutional change. Together they cast a very incisive, intense, and instrumental perspective over the whole of Mary Douglas' career. They acknowledge that her early ethnographic research is the very basis of her wide ranging theoretical interests (she firmly identified herself as an anthropologist) but the authors suggest that her influence was ultimately greater outside of her own discipline. In developing a neo-Durkheimian approach to show how the elements of social relations (and institutions) emerge from a dialectical pattern of mind and behaviour that can both control and spiral out of control, Douglas provided an analytic that allowed for comparative work on a broad scale. Her basis in ethnography grounds her theory in observing the world as it is, and not as it should be, but her close observation does suggest that the choices we make are the measure of how it might be.

Both Perri 6 and Paul Richards are interested in managing - organizations, government policy, conflict, epidemics, development projects and international relations. They work alongside practical agencies, think tanks, and decision makers in global enterprise. They find in Douglas' cybernetic modelling a way to measure success or failure in whatever field and along whatever aspiration is at hand. This is the very sort of judgement and control that many anthropologists have been moving away from since the last days of colonial administration where they once served as advisers. But what if we could apply what we have learned about how people across a wide range of societies and history have overcome the disturbances, anomalies, or calamities that disrupted their world and threatened to destroy it? This is perhaps the temptation as well as the risk to our discipline, and perhaps the basis for some resistance to Mary Douglas within anthropology.

The argument of the book is stated in the Preface and claims Mary Douglas as 'one of the most important theorists working in the social sciences in the twentieth century'. This is substantiated by a detailed reconstruction of her lifelong project to grasp the relation between how institutions work and how humans think, what causes conflict and how to resolve it. The book is well structured to hold the reader's interest and avoid cognitive fatigue brought on by excessive academic abstraction. This is achieved through what they call 'a broadly 
chronological life-and-works approach' (p.xii) allowing the reader to see the connections between her personal life and her career, the influence of her early ethnographic research leading to subsequent elaborations in comparative contexts - in other words, a detailed map of how Mary Douglas thought theory. She was intent on the task she set herself and followed where it took her, engaged with debate across a range of disciplines and was not dissuaded by popularity or the lack of it. She went so far as to stop further reprinting of excerpts from Purity and Danger because they '... tore these arguments from the context of the book's argument as a whole...' (p.25) even though her reputation was greatly enhanced by the success of that book. Perri 6 and Richards have perhaps gone almost too far in the other direction - an all inclusive, highly contextualized reading of her life and career from which a holistic, fully integrated theory emerges. As such, it can be applied in almost any situation because it is based on a theory of how humans think - all humans - and illustrated by how they behave. For Perri 6 and Richards this is not just theory, but an instrumental tool. To reach that point, Douglas herself had to use partial, secondary research as well as her own early ethnographic work. Anthropologists are trained to move from the particular to the general, and to see in difference, universal traits and behaviours that reassemble in a multitude of ways to construct what are merely variations on a common humanity. That is why we search for a theory, or theories, that work everywhere, even if the particulars may differ. But another set of problems can arise when we assume the scientific model of cause and effect for theory in the human sciences.

Chapter 1 covers the period between mid 1950s to the 1970s when Douglas began to develop key concepts from her fieldwork among the Lele of the Kasai. Perri 6 and Richards take a particular position in relation to the purpose of ethnography, or more to the point, the use of ethnography for their own purposes:

For a social theorist, the point of ethnography is not just to gather data about a particular case, but also to use this case as a microcosm for a much more general and, by implication, comparative argument. (p.19)

However, comparative theory building in social anthropology is a matter for critical debate, especially so when ethnography becomes bits of data filtered through a multi-disciplinary lens. And here is where the motivation of the authors of this book flow back and flood the field they have so carefully planted. In the subsequent four chapters, the book becomes confusing as the authors track back and forth between biographical details and the complex turns, reversals, loops and spirals of Douglas' theoretical thinking. 
Cited works by Mary Douglas are listed separately at the end of the book which does not claim to be a complete Bibliography of her work, but reminds the reader of its rich potential. Through it all her first fieldwork with the Lele remains as the golden thread to legitimate the rest. For many anthropologists, their extended fieldwork for their $\mathrm{PhD}$ carries the weight of their career in this way - the legitimating ethnographic experience.

ROMANCING THE FIELD

This brings me to the second book under review, Redescribing Relations: Strathernian Conversations on Ethnography, Knowledge and Politics edited by Ashley Lebner as a tribute to Marilyn Strathern now retired from the Cambridge Department of Social Anthropology and in recognition of the continuing influence of her research and writing. Strathern's bio (written in the third person p.61, p. 219) echoes the significance of the anthropologist's first fieldwork that we saw in Douglas'.

Marilyn Strathern had the good fortune to receive initial - and indelible - training in Papua New Guinea, which led to work, among other things, on kinship and gender relations (my emphasis).

The fieldwork on which a $\mathrm{PhD}$ is granted combined with the nature of that training - a deep immersion and identification with a community of people with a different culture, is taken as a transformational experience - almost a transfiguration that sets the anthropologist apart. The effect appears to be enduring and establishes the legitimacy of her future work. Like Douglas, Strathern develops theoretical and comparative propositions across history and culture, including contemporary western society. The initial field experience depends on the ability to grasp the difference while future work seems to rely on seeing cultures as not bounded and unique. Humans are universally culturemaking creatures along recognisable lines. But it is that primary ethnography - the ability to enter another world that gives authority to the anthropological voice. We even entrance, or romance, one another. Lebner describes the impact that a reading of Strathern's The Gender of the Gift had on her while conducting fieldwork in indigenous Northwest Amazonia:

... after long days spent with Hupde communities near the Tiquié River, every night for weeks I dutifully read The Gender of the Gift, holding it behind a candle stuck on the ground as I balanced in the hammock where I would later sleep. I didn't understand much of what I read at the time (nor did I realize that reading arrangement 
was preposterous for such a book), but perhaps the flickering candlelight seared some of it into memory: insights kept returning in later years, even after I had to change my field site and project due to complications with research permits. (p.viii)

As I write I am struck by reverie - recalling how I myself was marked in the field by reading Annette Weiner beside a flickering oil lamp, worrying over the difference between two fine Melanesianists - Weiner with her 'women of value, and Strathern's 'women in-between' (in my backpack), while searching for the meaning of Buka women on Bougainville.

\section{But I digress.}

\section{DESCRIPTION AND REDESCRIPTION}

Whereas Perri 6 and Richards see Mary Douglas in pursuit of a grand theory, Lebner sees Strathern as unconcerned with theory, rather, focusing on description or how people generate accounts of themselves which then becomes redescription, a method in anthropology. Theory, when present in Strathern's work is something to be tested - a hypothesis that is able to be disproven. And this enterprise, or critical conversation, in Strathern's terms, is all directed at 'getting the ethnography right' (p.2). Perhaps that is the main difference between these two books and their contributors. Richards and Perri 6 are looking to Douglas for a theory that can be actioned. Strathern's contributors are looking to get the ethnography right.

In her earlier review of Gender and the Gift Douglas wondered why Strathern chose such a complex structure when the same could be said of Douglas. In Douglas' case, her interlocutors suggest she was, in a looping weaving way, slowly building up to a grand, integrated theory. She took a long time to bring a theory to the boil. Strathern's work also takes time to mature. Not to mention loops and threads that appear in several chapters. As Lebner points out, Strathern,

... invites us not to replicate her redescriptive mode, but to practice an anthropology akin to hers, one that perennially rewrites what we think we know by enacting the particular sum of relations - the persons, places, various works and so on - we each encounter. (p.25)

This suggests a constant process rather than an instrumental conclusion. 
Chapter One is a transcribed interview, or better described as a conversation, between Marilyn Strathern, Eduardo Viveiros de Castro, and Carlos Fausto. This chapter alone is worth the price of the book for the insight it provides into the development of an anthropological career within a particular personal and intellectual history. At the end of their discussion, Strathern comments on her interest in 'the intellectual property stuff' that she says is 'taking Euro-American thinkers way, way into fields that the language just doesn't cope with. People are at the end of their conceptual tether.' (p.6o)

For this anthropologist (and others) un-tethered and somewhat lost in the complexity of some of Strathern's more recent writing, this chapter provides insights into the particular logic of her thinking in relation to some of her more difficult work (much as the above book on Mary Douglas does). Strathern is perfectly capable of writing clearly but increasingly presents us a with a maze of meaning instead of a clear map. Is she inviting us to get lost? Find a detour? A more interesting side line than she had thought of? (In this, Douglas is no help when she questions Strathern's 'scaffolding' in her review of The Gender of the Gift. In full tilt, both women are equally labyrinthine).

The following chapter by Carol Greenhouse ('The Scale(s) of Justice') takes on the Strathernian style of discourse that tangles ideas and concepts in the broad field of law, politics and bureaucracy. Stylistically this chapter favours clever word play, for example, 'E PLURIBUS PLURUM' as a heading for one subsection (and I am not sure who to blame for this) and confounds rather than clarifies what are significant current issues of civil rights and the authority of the state.

Chapter Three, 'Exchanging Equations: Anthropology as/beyond Symmetry' by Alberto Corsin Jiménez, is a model of clarity by comparison. He explores the idea that when theories are activated they don't work, with a focus on the proposition that with the coming of the digital age, we will see the advent of the paperless office. His ethnographic example is the resistance of a group of lawyers to company policy for a paper-less building with little shelf space for an archive:

For lawyers the paper form was a prototype of organizational knowledge... Between the proto and the type, the flow and the storage, the legal archive offered a place for knowledge to rest: where papers lay dormant, awaiting, perhaps, some future resurrection. (p.10o)

His tentative conclusion turns to the problem of anthropological knowledge itself and where it resides. Is it, 
...before, in between or against the trans-epistemological purchase of symmetrical equations? Perhaps the task of ethnography is more modest, after all, such as finding ways for redescription that breathe and transpire a certain 'inadequacy', that is, that are not ad-equate, where the entanglement of capacities and social forms does not mirror an exchange of equations. (p.101)

Like legal documents, the manner in which ethnography is stored may be significant. Handwritten notes, recordings, receipts, letters, photographs need to be archived in a physical form rather than merely digitised and therefore disembodied and too easily reconstituted to formulate a theory based on fractional facts.

Stuart Kirsch, in chapter 4, is interested in debates around the definitions of 'indigenous'. It was less problematic to colonial administrators when indigenous simply meant 'primitive', but since the word is now connected to human rights of a special nature and 'firstness', the concept has become contested on many planes. He sees this less of an issue for 'the settler states of New Zealand, Australia and the Americas' but problematic in different ways in societies with multiple overlapping claims to land as well as material or intellectual property on the basis of some fundamental primary ownership. Here Strathern's use of the concept of 'domains' and her 'strategy of creatively deploying unexpected juxtapositions' come in useful.

Chapter 5 by Yael Navaro ('Pacifist Devices') discusses Tech4Peace, a project created at the Cyprus Neuroscience and Technology Institute, that makes use of systems theory and cybernetics. This has led to the development of software like IT for peace. Another development in this area was the initiative of a Greek American systems scientist who produced software based on a 'structured dialogic design process' (SDDP) developed to mediate between conflicting parties. These are projects based on the potential for a humanist ethic. Perri 6 and Paul Richards also identify cybernetics as significant in Douglas' work towards developing a method, more instrumental in nature, for peaceful dialogue.

Chapter 6 by Jensen and Winthereik, 'Audit Loops and Audit Implosion', references Strathern's work on audit culture and is an ethnography of auditors that was in turn 'audited' by the auditors illustrating the risk of implosion.

As auditors saw it, this process helped to correct our mistakes, prevent flawed generalizations and clarify points of procedure. As we saw it, these interactions exemplified and mimicked the hybrid relation be- 
tween controller and counsellor that we aimed to characterize in the first place.... Recursively, the argument that we present has itself been subject to a version of the audit practice it describes. (pp.149-150)

They suggest their analysis of audit loops reveals that there is no end point and thus the power of the description of audit becomes challengeable simultaneously from within and without' (p.169). Surely though, this process is not without intent. The motive of the auditor is relevant - it cannot be a purely objective enterprise. To take another turn, or loop, when anthropologists submit their accounts or ethnographies back to their informants for comment, what are we trying to establish? Is our concern to 'get the ethnography right' fundamentally different from the audit culture we sometimes resent, and why?

Chapter 7 'Slow Motions [Extended Remix] Comments on a Few Texts by Marilyn Strathern' is by Eduardo Viveiros de Castro and Marcio Goldman with Selections and Translation by Ashley Lebner. This chapter is derived from a course taught by de Castro and Goldman. They acknowledge directly the difficult language that Strathern has developed:

... we are not in a rush, we are not trying to understand the texts of Marilyn Strathern hastily, because they are slow, hesitant texts, folded within themselves, texts that heave and halt and keep coming back to where they started. (p.174)

Time is not of the essence. This is also true of time in the field, they say, when often nothing is happening, there is a lot of waiting, hanging around until suddenly, unexpectedly, everything changes. The path to knowledge in anthropology is not straightforward they argue, and attempts to make it so, to fit in with the model of efficient production in university management ('the hell we have come to know only too well' p.175) seems to further justify and even politicise Strathern's somewhat recherché style. For my part, I tend to agree with Douglas - Strathern does not need all that scaffolding. (Not that Mary Douglas is always an easy read.)

Sarah Green's 'Conclusion: Thinking through Proliferations of Geometries, Fractions and Parts' finds Strathern's work 'simultaneously mind-bogglingly confusing and enormously thought-provoking' (p.198). Strathern ('Binary License') referred to Green's work in the Balkans as an example of plural logic stimulating Green to think more deeply into the dynamics of social life. One might have expected a concluding chapter to sum up the preceding contributions - but this was not the case. Nor was it a conclusion at all as it was followed 
by an 'Afterword' by Marilyn Strathern that seemed oddly out of place. The discussion here details organisational changes at the University of Cambridge in the relation between the William Wyse Professorship and the headship (HOD) of the Department of Social Anthropology. Strathern held that post for over ten years until her retirement. She says:

It is appropriate to end with a few words on the transformation to which Alan Macfarlane has pointed - the detachment of the William Wyse Professorship from the headship of the Department of Social Anthropology at the University of Cambridge... not a head at all but merely first among equals...' (p.209)

This leads her to a more general discussion of a focus on the person in British anthropology while the idea of office is all but effaced from British anthropological attempts to understand what was once called social organization' (p.210). Her example is set within the arcane particulars of Cambridge University but it seems true elsewhere that titles and promotions in academia have become disassociated from 'office' - the administration and management of the university system. In New Zealand universities disciplinary HoD's have gradually been subsumed into larger interdisciplinary administrative structures bureaucratic in nature and Professorships are awarded for personal achievement without a necessary responsibility for the discipline as a whole.

Reading these two books together, published in the same year by Berg, honouring the work of Dame Mary Douglas and Dame Marilyn Strathern, I imagined them as Boudicca warriors - originally as competitors for that grand title, but finally as first among equals.

\section{NOTES}

1 Dr Eleanor Rimoldi lectured in social anthropology at Massey University, Albany Campus for twenty-two years before retiring in 2015. She is currently Honorary Research Associate within the School of People, Environment and Planning. Her most recent publication is American Retrospective. Poems. 1961-2016. (Wellington: Hicksville Press 2018).

Email: eleanorrimoldi@gmail.com

2 London Review of Books, Volume 11 (9), 4 May 1989 